ÉGYPTE monde arabe

\section{Égypte/Monde arabe}

$10 \mid 1992$

Partage de l'eau dans le monde arabe

\title{
L'ultime port. L'ultime scintillement
}

\section{Gamâl al-Ghitânî}

Traducteur : Alain Roussillon

\section{OpenEdition \\ Journals}

Édition électronique

URL : https://journals.openedition.org/ema/1424

DOI : 10.4000/ema. 1424

ISSN : 2090-7273

Éditeur

CEDEJ - Centre d'études et de documentation économiques juridiques et sociales

Édition imprimée

Date de publication : 30 juin 1992

Pagination : $143-146$

ISSN : 1110-5097

Référence électronique

Gamâl al-Ghitânî, «L'ultime port. L'ultime scintillement », Égypte/Monde arabe [En ligne], 10 | 1992, mis en ligne le 08 juillet 2008, consulté le 07 juillet 2022. URL : http://journals.openedition.org/ema/1424 ; DOI : https://doi.org/10.4000/ema.1424

Ce document a été généré automatiquement le 7 juillet 2022.

Tous droits réservés 


\title{
L'ultime port. L'ultime scintillement
}

\author{
Gamâl al-Ghitânî \\ Traduction : Alain Roussillon
}

\section{NOTE DE L'ÉDITEUR}

Note du traducteur : Texte extrait de Khitat Ghitâni, traduit de l'arabe par Alain Roussillon. Nous avons rendu - fort improprement - par « cité » le terme arabe khitat qui constitue le titre du roman de Gamâl al-Ghitânî, dont on donne ici à lire les toutes dernières pages. Khitat désigne tout d'abord la texture même d'un tissu urbain dont la cohésion et les fractures renvoient à une appartenance fragmentée - à mi-chemin, si l'on veut, entre "quartier » et « territoire », camp retranché dont les portes et les frontières peuvent bien n'être que métaphysiques, mais n'en demeurent pas moins fondatrices d'appartenance et de reconnaissance ou d'exclusion. À un second niveau, Khitat désigne un "genre littéraire », tradition d'écriture et d'appréhension du réel urbain, à travers laquelle Gamâl al-Ghîtânî revendique une filiation où son texte fait écho aux Khifaî tawfiqiyya, de 'Ali Mubârak, el à celles, fondatrices, d'Al-Maqrîzî (1363-1442/765-845 h.)

1 Voici qu'est échu le temps des chroniques et des calamités. Voici que ma tête a blanchi et que mon cœur a pris la couleur des tréfonds. Ô nostalgie de la belle cité, de ses jours heureux, de son fleuve scintillant. De ses retraites inviolées dont les propagateurs de mensonges vont jusqu'à nier l'existence. Ô nostalgie des soirs de veille, des ombrages, de l'écho des rires au coin des rues automnales. Nostalgie des nuits, de la torpeur du méridien, des instants de profusion. De ces journées radieuses - soleil naissant, au zénith ou déclinant. De sa salive au goût de musc. Nostalgie du premier instant, quand y reviennent les voyageurs. De l'embrasement du crépuscule. Des mystères d'un passé révolu. Du vague dans les yeux des femmes. ô nostalgie nostalgie...

La cité s'est évanouie comme s'évanouit toute beauté, ô ma douleur... Ou bien n'était-ce qu'un pur fantôme, un rêve qui se dissipe comme s'évapore la rosée? Un immense caravansérail ouvert au tout-venant, qu'on quitte comme on y est entré, avant que 
n'advienne le jour de la promesse. Informe-moi. Explique-moi. Ouvre-moi les yeux. Guide-moi. Regard immuable, œil que rien n'abuse. Est-il vrai qu'elle est tombée sous l'emprise de gens qui ne l'aiment pas, de gens qui la détestent? Est-il vrai qu'ils l'ont effacée d'un trait de plume dans des registres secrets, qu'ils l'ont vendue à vil prix pour le compte de banques lointaines et sourdes? Est-il vrai que ne subsistent plus que d'amères chroniques? Que la mer a tout recouvert, anéantissant tout ce qui pousse et croît ? Tout ce qui pousse et croît ; l'instant où naissent les bourgeons et s'ouvrent les fleurs. Au secours. Au secours. Au secours...

3 Il ne reste plus que l'espace du néant, que le dialogue des sourds et des muets, que des aveugles qui ne voient qu'eux-mêmes et ce qui va s'évanouissant. Le point du jour se mêlant au soleil couchant. Les accès de la ville, comme le col d'un utérus ne laissent passer qu'une personne à la fois. Voici qu'approche le moment d'inscrire le point final. Les vents ont tourné en faveur des ennemis de la cité et comblé leurs espérances. Ses habitants, eux, ne connaissent plus que l'effroi et la peur qui les consument. Vint le jour ou l'on n'en rencontra plus que se lamentant ou pleurant, blessés, morts ou affligés. Ils ont déserté les endroits les plus plaisants qui avaient été leurs pendant des lustres. Le voyage leur est devenu facile et l'exil acceptable. Vague après vague, ils ont été dispersés aux quatre coins de l'univers, si bien que sept habitants de la cité ne purent être réunis en un même endroit. Les herbes folles ont envahi des terres qui furent, un jour, habitées. Les épines ont tout recouvert tandis que s'accumulaient en tous lieux de tristes décombres : restes de tables et de matelas, miroirs et tambourins, cahiers et cartes postales, bannières et encensoirs, jeux d'enfants, crayons, livres qui furent sacrés. Au pourtour de la cité les hiboux ont niché et les corbeaux se sont multipliés là où croissaient les plantes et gîtaient les pigeons.

Vient le jour où le fleuve enfle et déborde, où la terre se fissure avec la fertilité d'une femelle prolifique et pourtant nul ne bouge ni ne laboure. Les ennemis sont venus avec des tuyaux de plastique, ils ont aspiré les eaux e arraché le limon jusqu'à ce qu'apparaissent les entrailles de la terre. Avec ce qui faisait la fertilité de notre cité ils ont irrigué leurs déserts. Ô mon amertume ! Puis ils ont confisqué ce qui restait. Là réside le mystère : la mer a commencé à recouvrir la terre, grignotant les franges de la cité. Les eaux se sont répandues, sans que rien ne les arrête ou leur résiste. Une avancée inexorable et calme, comme de minces filaments mais qui recouvriraient tout. Avec les jours noirs qui passent elles acquièrent une sombre profondeur dans laquelle nagent les nuages du ciel. (...)

5 Al-Khidr ${ }^{1} n^{\prime}$ est pas mort. Les photos de son cadavre qui ont été publiées sont falsifiées. Les doigts amputés qu'ils ont exhibés en disant qu'ils portaient ses empreintes ne sont pas les siens. Al-Khidr n'est pas mort et ne mourra pas. Il se manifeste tous les jours auprès des ponts de l'aube et aux confins du midi. Il se déplace sur les souffles du vent et se change en lumière sur les éminences désolées. Il y rencontre Salomon, natif de la rue des surprises, l'homme de tous les coups durs et le gardien des principes de la cité, de ses mots, et de tout ce qui résiste. Le reste du jour, il le passe à réconforter les habitants de la cité, les émigrés, les exilés. Elie, quant à lui, se charge de la nuit. Puis ils se retrouvent, avec Salomon, juste avant l'aube, dans un endroit que n'ont pas recouvert les eaux, pour s'assurer que l'unique entrée de la grande caverne reste bien accessible et assister à l'envol du grand oiseau vert qui apaise leurs cœurs.

6 Ô gens... Ô habitants de la cité qui avez bu jusqu'à la lie le calice d'amertume, vous qui tentez de reconstituer, poignée après poignée, le limon de fertilité et de reféconder la 
terre recouverte par les eaux salées... Tous les jours la superficie du limon s'étend. La caverne demeure inviolée, tout comme les glorieuses momies. Le tableau de ToulouseLautrec lui aussi est intact. Il y a les talismans, les charmes, les évangiles et les corans, les anciens psaumes et les livres de sagesse, les préceptes authentiques et les dispositions innées.

7 Ô gens... Al-Khidr, Elie et Salomon ne mourront pas car ils se sont abreuvés aux sources secrètes de la vie de la cité, Ils ont traversé les flammes éternelles. Regardez... Regardez donc ! La cité est là qui resplendit et son secret perdure. Ses fondements sont intacts. Maintes fois, dans le passé, tes flots l'ont recouverte, mais toujours il s'est trouvé des héros inflexibles pour la délivrer. Elle est l'ultime port, l'ultime scintillement. Comment ne le voyez-vous pas?

Des mains applaudissent. Le cri secret se perd. Bruit de pas. Yeux fixes. Hurlement d'un homme étranger à la ville.

Que reviennent les jours du combat ! Regret de ses derniers jours dans la cité. Hurlement.

Au secours... Au secours... Au secours.

\section{NOTES}

1. AI-Khidr : personnage mythique, mi-archange, mi-prophète, dont la rencontre, qui ne peut se produire qu'une seule fois dans une vie d'homme, est à la fois signe de la faveur divine et mise à l'épreuve. Le prophète Elle est réputé être contemporain de toutes les époques. Quant à Salomon, il est l'incarnation de toute sagesse possible.

\section{INDEX}

Mots-clés : al-Ghitânî (Gamal), littérature 